\title{
Durability of PEMFC Electrodes and Reduction of Pt Loading
}

\author{
P. Gazdzicki ${ }^{1}$, J. Mitzel ${ }^{1}$, D. G. Sanchez ${ }^{1}$, A. M. Dreizler ${ }^{1}$, M. Schulze ${ }^{1}, \underline{\text { K. A. Friedrich }}{ }^{1,2}$ \\ ${ }^{1}$ German Aerospace Center (DLR), Institute of Engineering Thermodynamics, Stuttgart, Germany \\ ${ }^{2}$ University of Stuttgart, Institute of Energy Storage, Stuttgart, Germany
}

A particular challenge related to low temperature polymer electrolyte fuel cells (PEMFC) is to maintain high performance and long-term durability concurrently with the further reduction of $\mathrm{Pt}$ loading. These are conflicting goals because of a direct correlation of $\mathrm{Pt}$ surface with activity and $\mathrm{Pt}$ amount with durability. Moreover the lack of common procedures to reliably determine voltage loss rates leads to severe difficulties in the comparison of results obtained by different institutions or projects. Accordingly, special attention is devoted to the discrimination between irreversible and reversible voltage losses [1].

Regarding the influence of Pt loading on PEMFC performance and durability our recent rainbow stack study [2] performed in dynamic operation shows that for $\mathrm{Pt} / \mathrm{C}$ based cathodes a sudden drop of performance is observed for loadings $<=0.2$ $\mathrm{mg}_{\mathrm{Pt}} \mathrm{Cm}^{-2}$ and current densities $>1 \mathrm{Acm}^{-2}$. A similar threshold value is found for the increase of irreversible voltage losses

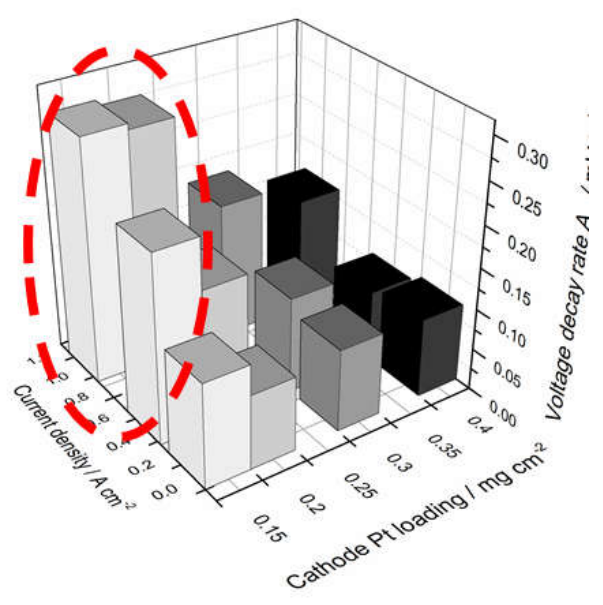

Fig. 1: Irreversible voltage decay rate as a function of current density and cathode Pt loading. which lead to a reduction of PEMFC durability for cathodes with $<=0.2-0.3 \mathrm{mg}_{\mathrm{Pt}} / \mathrm{cm}^{2}$ (see Fig. 1). Another durability issue at cathodic loadings $<0.4 \mathrm{mg}_{\mathrm{pt}} / \mathrm{cm}^{2}$ is the acceleration of reversible degradation leading to a significant voltage drop at continuous fuel cell operation. The results show that the $\mathrm{Pt}$ loading of $\mathrm{Pt} / \mathrm{C}$ based electrodes cannot be reduced below $0.2-0.3$ $\mathrm{mg}_{\mathrm{Pt}} \mathrm{Cm}^{-2}$ by just varying the thickness of the catalyst layers without suffering durability issue. To go below

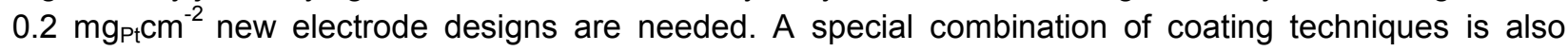
considered as promising approach to solve this issue.

The research leading to these results has received funding from the European Union's Seventh Framework Programme (FP7/2007-2013) for Fuel Cell and Hydrogen Joint Technology Initiative under Grant No. 303452 (Impact).

\section{References:}

[1] P. Gazdzicki, J. Mitzel, D. Garcia Sanchez, M. Schulze, K. A. Friedrich, J. Power Sources, 327, 85 (2016).

[2] P. Gazdzicki, J. Mitzel, A. M. Dreizler, M. Schulze, K. A. Friedrich, Fuel Cells, DOI: 10.1002/fuce.201700099 